\title{
Liquid crystalline organic semiconductors for organic transistor applications
}

\author{
Hiroaki Iino and Jun-ichi Hanna
}

The recent development of materials for organic field effect transistors (OFETs), including small-molecule and polymer materials, are briefly reviewed, and the problems that remain to be solved prior to practical application and use are discussed. Liquid crystalline materials are good candidates for OFETs because of their advantageous properties over soluble small-molecule materials. Liquid crystalline materials show good solution processability for the fabrication of uniform crystalline thin films using the precursor of uniform liquid crystalline thin films. In addition, liquid crystalline materials having their highly ordered liquid crystal phases show a high thermal durability despite their high solubility. The novel liquid crystalline material 2-phenyl-7-decyl [1]benzothieno[3,2-b][1]benzothiophene exhibits a highly ordered liquid crystal phase, the Smectic E (SmE) phase, which has good solution processability for uniform crystalline thin films by the precursor of uniform SmE thin films, shows high thermal durability and solubility, and can be used for transistor devices having a high mobility, over $10 \mathrm{~cm}^{2} \mathrm{Vs}^{-1}$, by thermal annealing at $120^{\circ} \mathrm{C}$ for $5 \mathrm{~min}$. Thus, liquid crystalline materials are good semiconductor materials for organic transistor applications instead of polymer materials.

Polymer Journal (2017) 49, 23-30; doi:10.1038/pj.2016.101; published online 12 October 2016

\section{INTRODUCTION}

Materials for organic field effect transistors (OFETs) have attracted considerable attention since their high mobility of over $1 \mathrm{~cm}^{2} \mathrm{Vs}^{-1}$, comparable to that of amorphous silicon FETs, was reported in polycrystalline thin films of pentacene fabricated by vacuum evaporation. ${ }^{1}$ OFETs are very attractive for device applications because they can be fabricated even at room temperature to create flexible electronics on plastic substrates. Recent materials research for OFETs has been focused on soluble OFET materials because of their device applications in printed electronics. In this review, the recent development of OFET materials is briefly discussed, including the use of small molecules and polymers, and the remaining problems to be solved for their practical applications are discussed. Then, a new candidate for OFET materials, that is, liquid crystals, as a self-organizing molecular semiconductor, is discussed, focusing on how liquid crystallinity can solve the existing problems, and its high potential for OFET applications is demonstrated with a highly ordered smectic liquid crystal of 2-phenyl-7-decyl[1]benzothieno[3,2-b][1] benzothiophene (Ph-BTBT-10). ${ }^{2}$

\section{SMALL-MOLECULE OFET MATERIALS}

For high mobility, molecules with an extended $\pi$-conjugate system as represented by pentacene are considered promising. ${ }^{1}$ However, such materials show poor solubility in common organic solvents because of their strong $\pi-\pi$ interactions. In the 2000s, materials research for
OFETs became focused on not only high mobility but also improved solubility in common organic solvents. Various soluble small-molecule $\mathrm{p}$-channel and n-channel OFET materials have been proposed, such as TIPS-Pentacene, ${ }^{3} \mathrm{C}_{8}$-BTBT, ${ }^{4} \mathrm{C}_{10}$-DNTT, ${ }^{5} \mathrm{C}_{10}$-DNT-VW, ${ }^{6}$ $\mathrm{C}_{10}$-DNBDT $^{7}$ and PTCDI-C13, ${ }^{8}$ as shown in Figure 1 , in which the $\pi-\pi$ interaction of the extended $\pi$-conjugate system is weakened to improve the solubility by incorporating either long alkyl chains, a bulky moiety or an asymmetric molecular shape around the molecular axis. OFETs with these crystalline films fabricated by a solution process show high FET mobilities over $1 \mathrm{~cm}^{2} \mathrm{Vs}^{-1}$.

However, there are two issues that remain to be resolved in soluble small-molecule OFET materials. One is the poor uniformity and surface morphology of crystalline films because of the random recrystallization of the OFET materials on the substrate during the solvent evaporation, which results in a wide variation in the FET performance from device to device in large-scale circuits. The other is the thermal durability of the films, particularly in soluble OFET materials that are chemically modified with long alkyl chains, in which the melting point is significantly reduced; for example, the melting point is ca. $200{ }^{\circ} \mathrm{C}$ in BTBT, ${ }^{9}$ but it is reduced to ca. $100{ }^{\circ} \mathrm{C}$ in dialkyl BTBTs. ${ }^{4}$ The adoption of larger core systems such as $\mathrm{DNTT}^{5}$ and $\mathrm{DNBDT}^{7}$ unfortunately always result in poor solubility because of a trade-off between the solubility in solvents and the melting point, so that it is quite difficult to satisfy both requirements. 

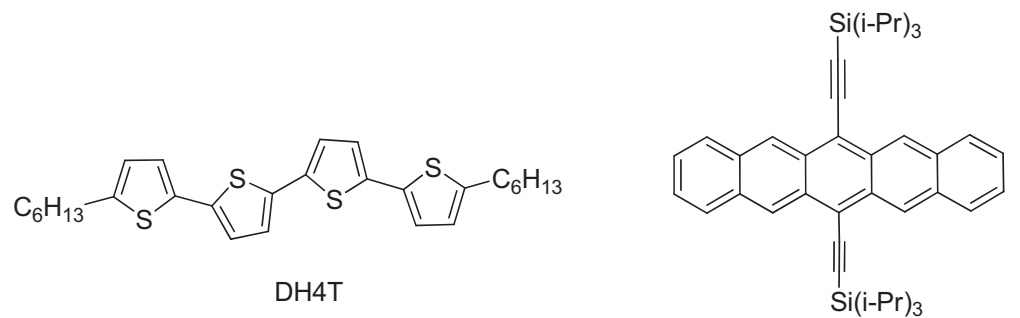

TIPS-Pentacene

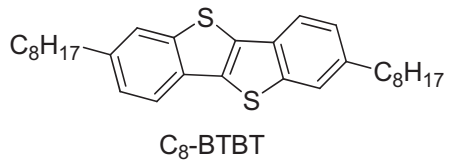<smiles>CCCc1ccc2cc3c(cc2c1)sc1cc2cc(C=O)ccc2cc13</smiles>

$\mathrm{C}_{10}$-DNT-VW
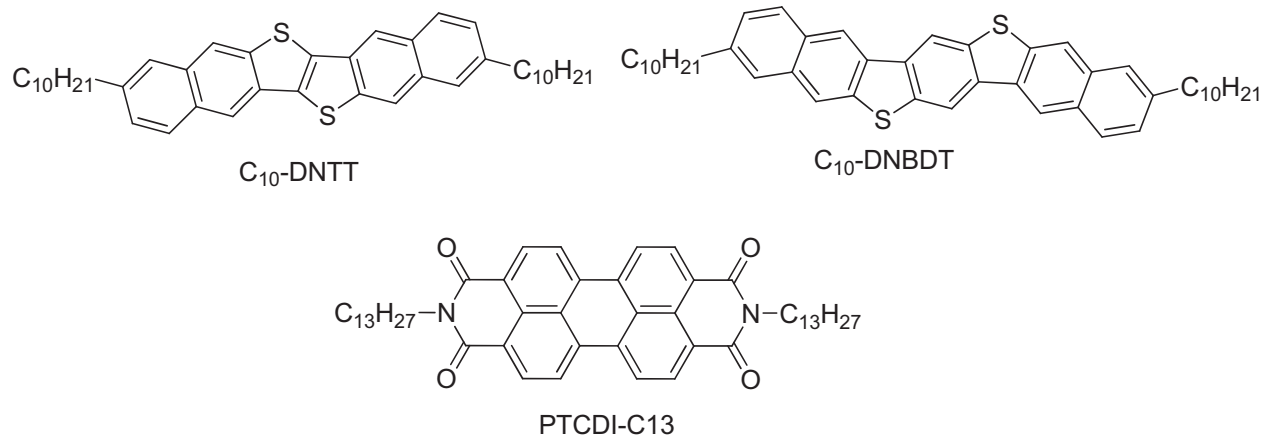

Figure 1 Chemical structures of typical soluble crystalline small-molecule materials for organic transistors.<smiles>CCCCCCc1cc(C)sc1C(C)(C)C</smiles>

$\mathrm{P} 3 \mathrm{HT}$<smiles>CCCCCCCc1cc(C)sc1-c1cc2sc(-c3sc(C)cc3CC)cc2s1</smiles>

PBTTT

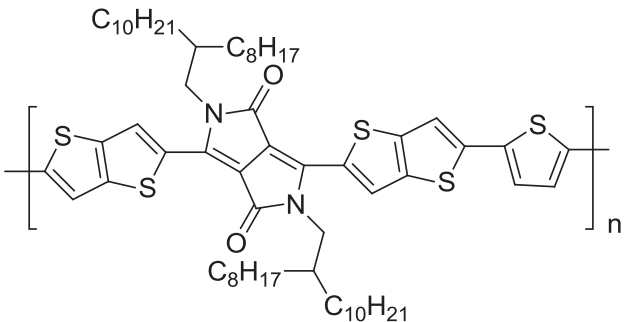

DPP polymer

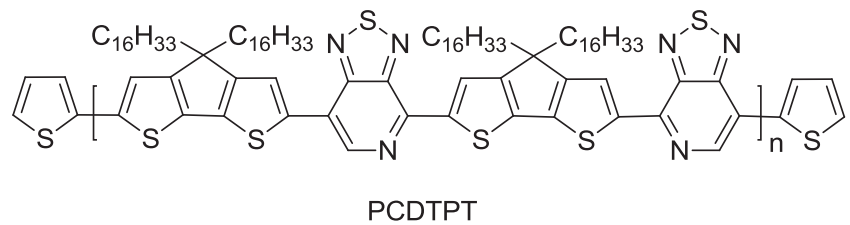

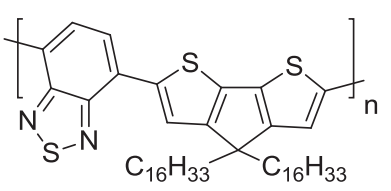

CDT-BTZ-C 16

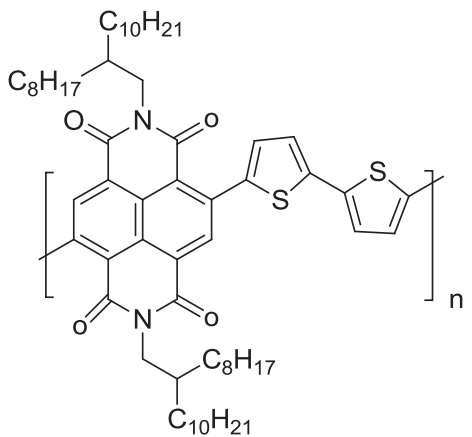

$\mathrm{P}(\mathrm{NDI}$ 2OD-T2)

Figure 2 Chemical structures of typical polymer materials for organic transistors. 


\section{POLYMER OFET MATERIALS}

In the 1980 s, films of $\pi$-conjugated main-chain polymers such as polythiophene derivatives were proposed for OFETs, but the FET mobility was limited to $10^{-5}$ to $0.1 \mathrm{~cm}^{2} \mathrm{Vs}^{-110,11}$ because of the poor crystallinity of the films. In the 2000s, to improve the molecular orientation and crystallinity of the films, the use of regioregular polythiophene (P3HT) was proposed, and the mobility was improved up to $0.1 \mathrm{~cm}^{2} \mathrm{Vs}^{-1} .12$ Then, a liquid crystalline polymer of poly(2,5-bis(3-alkylthiophen-2-yl)thieno[3,2-b]thiophene was synthesized, and the mobility was improved up to $0.6 \mathrm{~cm}^{2} \mathrm{Vs}^{-1}$ after thermal annealing at $180{ }^{\circ} \mathrm{C}$ for $15 \mathrm{~min}^{13}$

Recently, the use of a new type of $\pi$-conjugated main-chain polymer, that is, donor-acceptor (D-A) polymers (for example, CDT-BTZ- $\mathrm{C}_{16}$ and DPP polymers), was proposed, which is a breakthrough in polymer OFET materials because of their high mobility of over $1 \mathrm{~cm}^{2} \mathrm{Vs}^{-1} \cdot{ }^{14,15} \mathrm{P}(\mathrm{NDI} 2 \mathrm{OD}-\mathrm{T} 2)$ was proposed as an $\mathrm{n}$-channel OFET material and showed a high mobility of $0.2 \mathrm{~cm}^{2} \mathrm{Vs}^{-1} \cdot{ }^{16}$ More recently, Tseng et al. ${ }^{17}$ obtained very high mobility $\left(\sim 20 \mathrm{~cm}^{2} \mathrm{Vs}^{-1}\right)$ using PCDTPT polymer. Figure 2 shows examples of polymer materials that exhibit high FET mobility.

The polymer OFET materials have a great advantage over smallmolecule OFET materials in terms of their film-forming ability and thermal durability due to the high molecular weight of the long molecules. However, the control of the molecular alignment in the films is not easy for the same reason, necessitating thermal annealing at a high temperature, often at $200{ }^{\circ} \mathrm{C}$, and/or special surface treatment to improve the molecular orientation both on the substrate and in the source-drain electrodes. Other problems in the use of polymer materials are their reproducibility of synthesis and purification compared with that of small molecules.

\section{LIQUID CRYSTALS AS OFET MATERIALS}

Liquid crystals entered the family of organic semiconductor materials after the discovery of electronic conduction in their mesophases in the 1990s. However, little attention was paid to them in spite of their easy fabrication into uniform films and the easy control of their molecular orientation in a self-organized manner. In the 2000s, liquid crystals were reported as organic transistor materials. Liquid crystals can be used to fabricate OFETs in either liquid crystalline or crystalline thin films because they exhibit both phases at different temperatures.

Garnier et al. ${ }^{18}$ studied OFETs of dialkyl-oligothiophene derivatives, in which the alkyl chains attached to an oligothiophene affected the solubility and the molecular assembly of the molecular layers, and OFETs of dihexyl-quaterthiophene, which showed a liquid crystal phase, that were fabricated by spin-coating at a high temperature. ${ }^{19,20}$ The Phillips research group then studied thienylethynyl-terthiophene derivatives as liquid crystalline organic semiconductors and succeeded in fabricating single-domain crystalline OFETs by a phase transition from a nematic phase on an alignment layer, ${ }^{21}$ whereas Funahashi et al. $^{22}$ reported the FET performance in the liquid crystalline phase of a phenyl-terthiophene derivative (3-TTP-Ph-5). The FET mobility of these FETs was up to $10^{-2} \mathrm{~cm}^{2} \mathrm{Vs}^{-1}$.

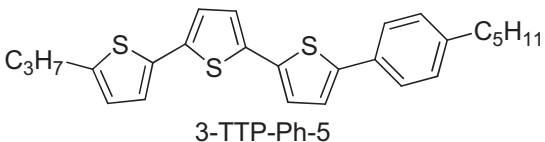

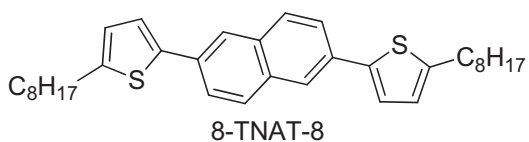
8-TNAT-8<smiles>CCCCCCCc1ccc(-c2ccc3cc4cc(-c5ccc(-c6ccccc6)s5)ccc4cc3c2)s1</smiles><smiles>CCCCCCc1ccc(C#Cc2ccc(-c3ccc(-c4ccc(C#Cc5ccc(CCCCC)s5)s4)s3)s2)s1</smiles>

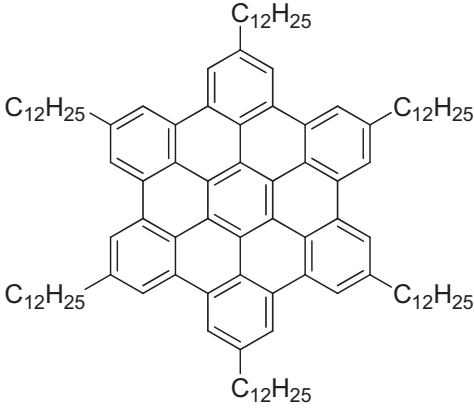
thienylethynyl-terthiophene

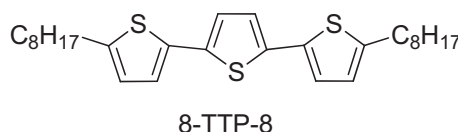

8-TTP-8<smiles>c1csc(-c2ccc3c(c2)sc2c4ccccc4sc32)c1</smiles>

8-Tp-BTBT

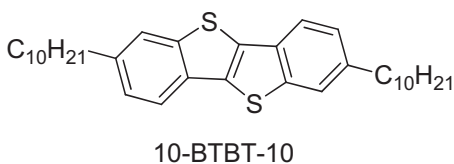<smiles>CCCCCCc1ccc2c(c1)sc1c3ccc(-c4ccccc4)cc3sc21</smiles>

Ph-BTBT-10

Figure 3 Chemical structures of typical liquid crystalline materials for organic transistors. 
There have been many reports on the FET performance of OFETs fabricated from crystalline thin films of liquid crystals including di-thienyl-naphthalene, ${ }^{23}$ hexabenzocoronene, ${ }^{24}$ bis-(5'-hexylthiophen2'-yl)-2,6-Anthracene ${ }^{25}$ and dialkyl-BTBT derivatives, ${ }^{4}$ as shown in Figure 3. However, the liquid crystallinity in these materials was overlooked, and its benefits have not been utilized in device fabrication.

We have studied liquid crystals as a self-organizing molecular semiconductor since we discovered electronic conduction in a smectic liquid crystal of phenyl-benzothiazole derivatives ${ }^{26,27}$, and observed that the unique properties of liquid crystals could be utilized in film fabrication processes for the improvement of various important properties of OFET materials. It is worth noting that the liquid crystallinity that often appears in soluble OFET materials is not accidental but, quite possibly, occurs because the molecular design of chemical modification with long alkyl chains for the enhancement of the solubility, as described above, is the same strategy as the molecular design for liquid crystalline materials. Hereafter, we discuss how the liquid crystallinity in OFET materials can be utilized, based on our studies.

\section{Solution processability of liquid crystals}

Smectic liquid crystals exhibit a soft nature compared with crystalline materials and tend to align vertically on a substrate in a self-organized manner because of their anisotropic molecular structure, also exhibiting high solubility in organic solvents because of their long side chains. These properties are quite helpful for the solutionprocessing fabrication of thin films. In fact, very uniform and
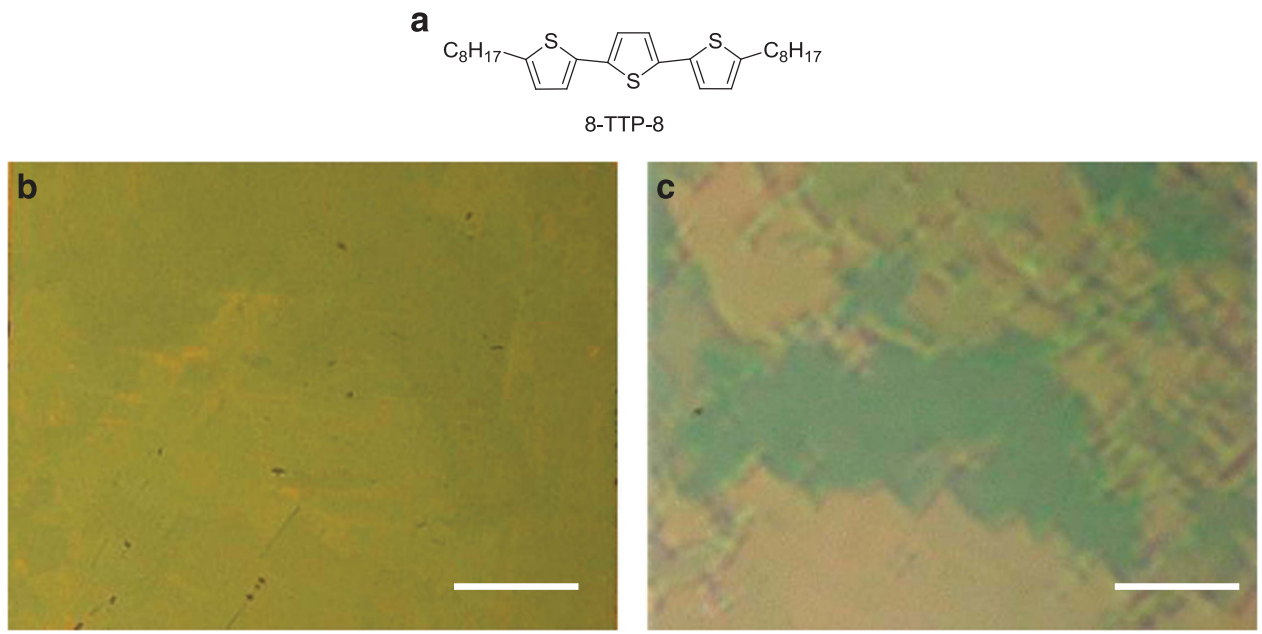

Figure 4 Textures of polycrystalline thin films of 8 -TTP- 8 fabricated by spin-coating in the liquid crystal phase at $85^{\circ} \mathrm{C}$ from a 1 wt $\%$-xylene solution. White bars indicate a 20- $\mu \mathrm{m}$ length. (a) Chemical structure of 8-TTP-8, (b) texture from optical microscopy and (c) texture from polarized optical microscopy.
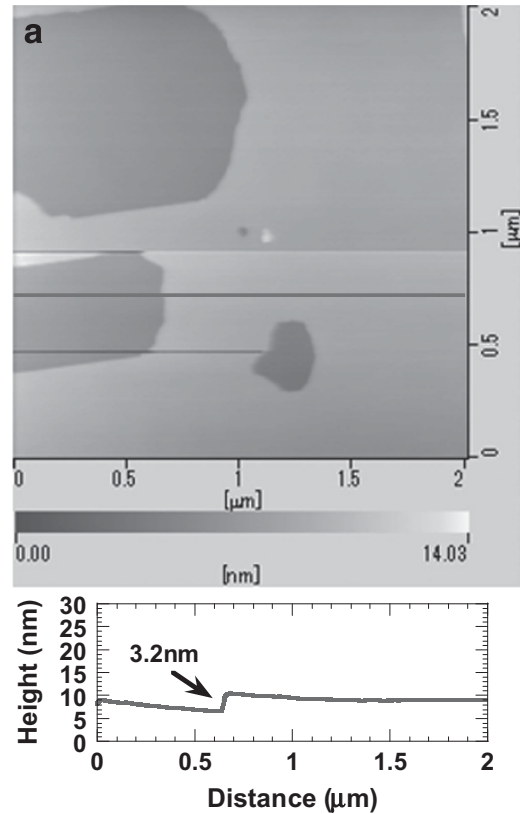

b

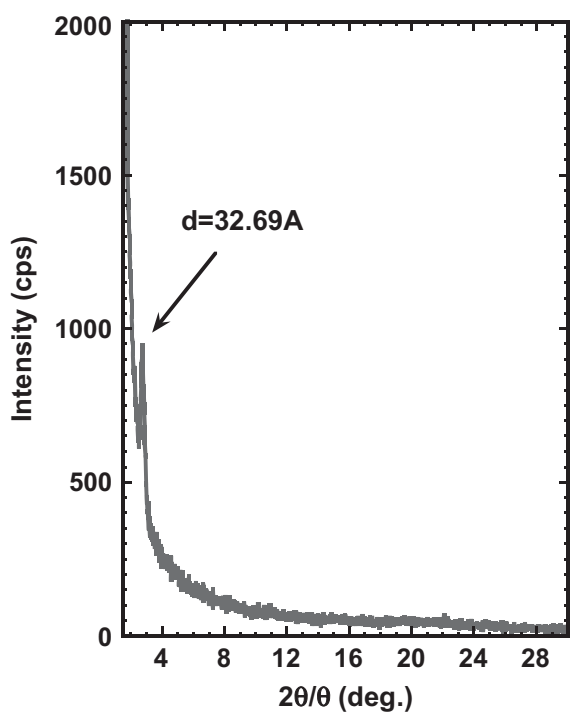

Figure 5 Surface morphology and molecular alignment of polycrystalline thin films of 8-TTP-8. (a) Topo image observed by atomic force microscopy. (b) X-ray diffraction pattern in out-of-plane configuration. A full color version of this figure is available at Polymer Journal online. 


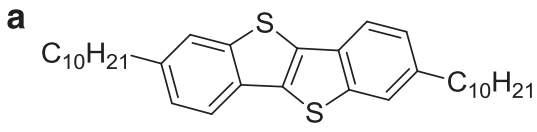

10-BTBT-10<smiles>c1csc(-c2ccc3c(c2)sc2c4ccccc4sc32)c1</smiles>

8-Tр-BTBT
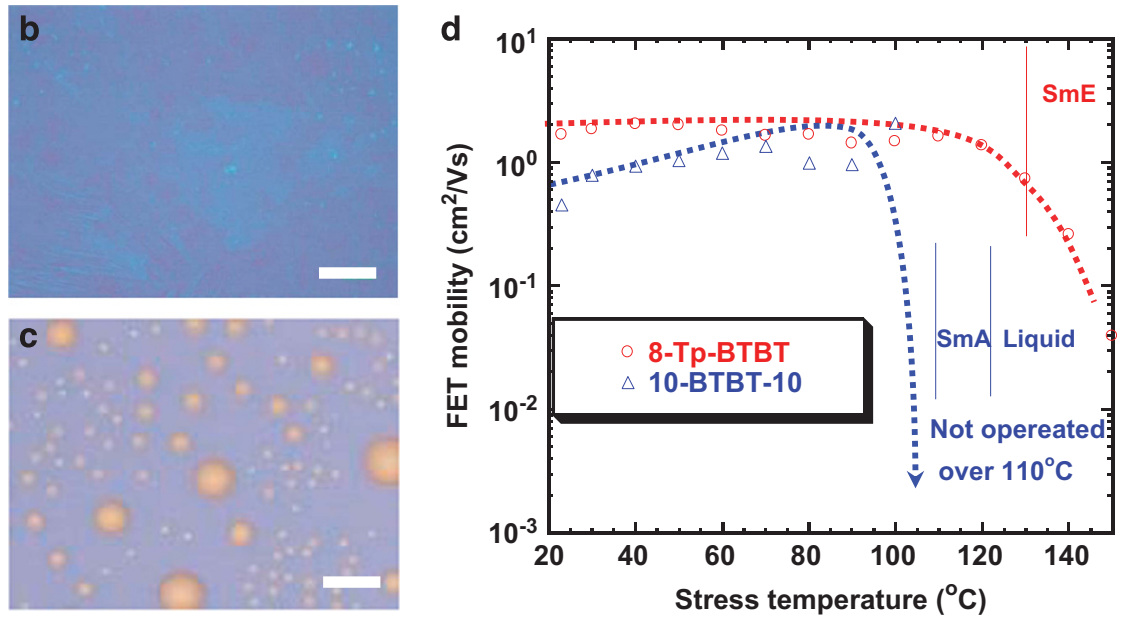

Figure 6 Optical microscopy textures and field effect transistor (FET) mobilities of polycrystalline thin films of two BTBT derivatives after being subjected to thermal stress at $150^{\circ} \mathrm{C}$. (a) Chemical structures of 10-BTBT-10 having only Smectic A (SmA) and 8-Tp-BTBT having Smectic E (SmE) phases, textures of (b) 8-Tp-BTBT and (c) 10-BTBT-10. (d) FET mobilities of 8-Tp-BTBT and 10-BTBT-10 as a function of stress temperature. White bars indicate 20- $\mu \mathrm{m}$ length.

a<smiles>CCCCCCCc1ccc2c(c1)sc1c3ccc(-c4ccccc4)cc3sc21</smiles>

Ph-BTBT-10

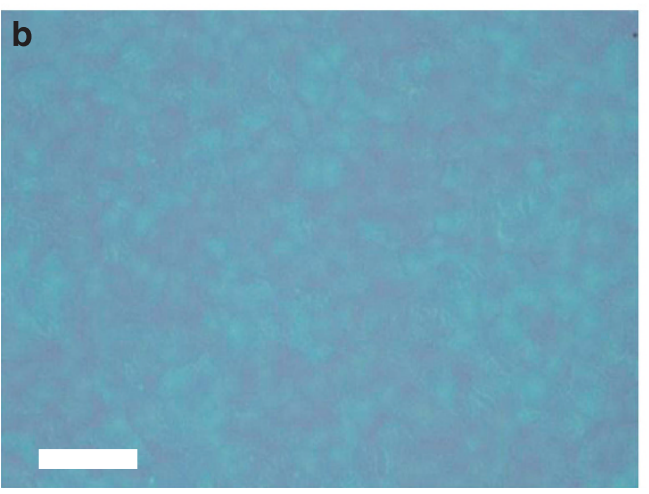

c
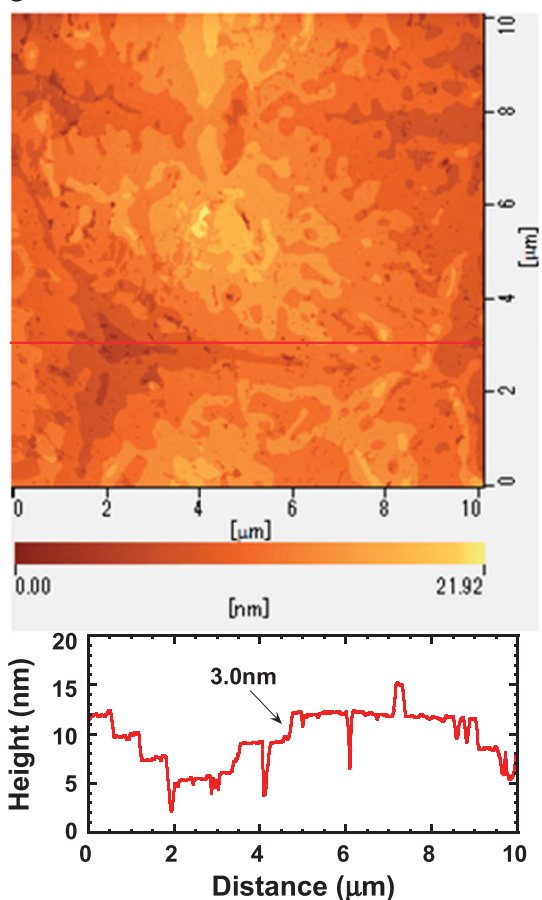

Figure 7 Characteristics of polycrystalline thin films of 2-phenyl-7-decyl[1]benzothieno[3,2-b][1]benzothiophene (Ph-BTBT-10) fabricated by spin-coating at liquid crystal temperature. (a) Chemical structure, (b) optical microscopy texture and (c) topo image observed by atomic force microscopy at room temperature. White bars indicate $20-\mu \mathrm{m}$ length.

molecularly flat films can be prepared by spin-coating a liquid crystalline solution on a substrate at a mesophase temperature. The resulting liquid crystalline films are easily transformed to crystalline films just by cooling them down to their crystallization temperature.
Therefore, liquid crystalline films can be utilized as a precursor film for crystalline films. This was demonstrated with a liquid crystalline terthiophene derivative of 8 -TTP-8. ${ }^{28,29}$ Figure 4 shows optical and polarized microscope images of the texture of a polycrystalline thin 
a

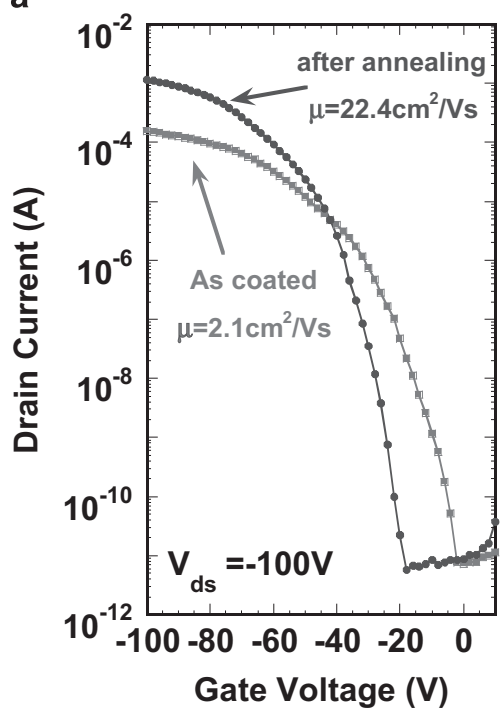

b

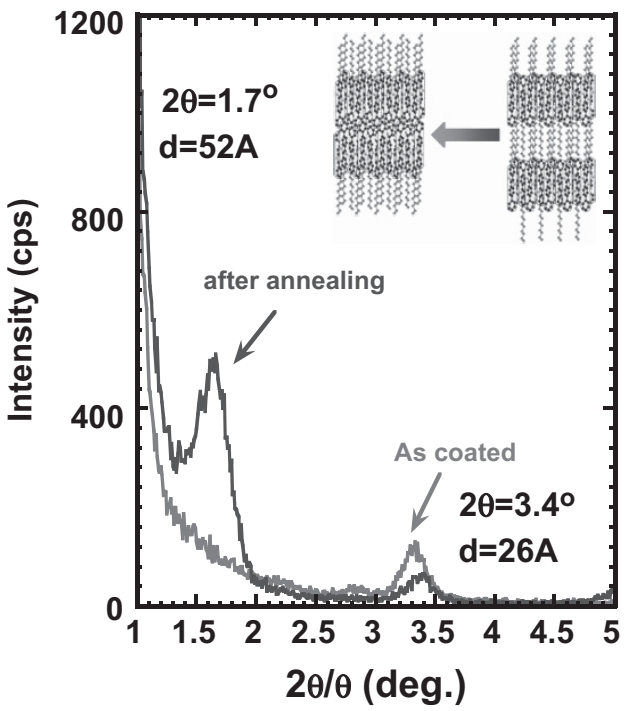

Figure 8 Characteristics of polycrystalline thin films of 2-phenyl-7-decyl[1]benzothieno[3,2-b][1]benzothiophene (Ph-BTBT-10) fabricated by spin-coating at liquid crystalline temperatures, as-coated and after thermal annealing at $120^{\circ} \mathrm{C}$ for $5 \mathrm{~min}$. (a) Transfer characteristics of bottom-gate top-contact type field effect transistor (FET). (b) Small-angle X-ray diffraction pattern. A full color version of this figure is available at Polymer Journal online.

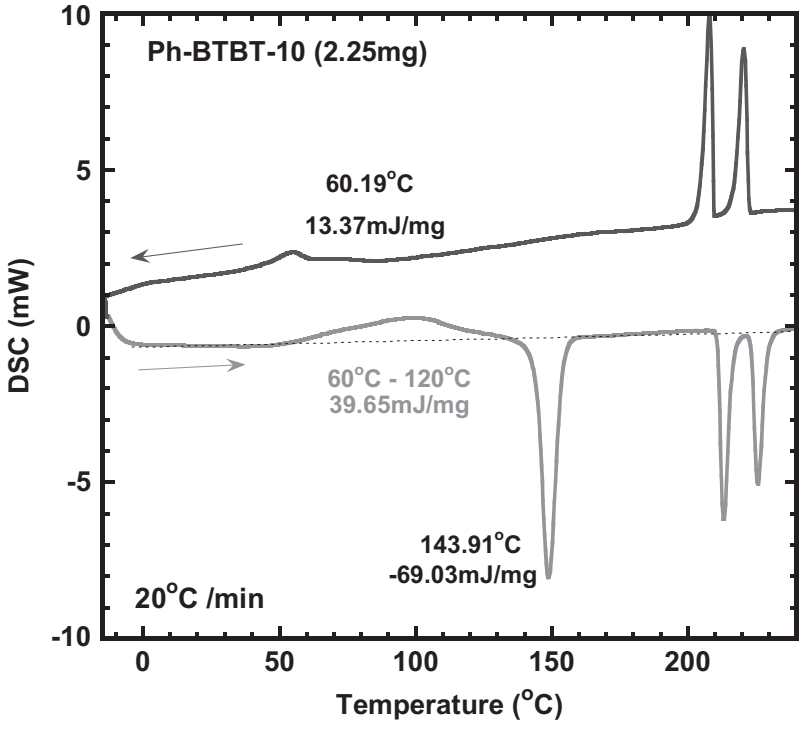

Figure 9 DSC curve of 2-phenyl-7-decyl[1]benzothieno[3,2-b][1] benzothiophene (Ph-BTBT-10) at $20^{\circ} \mathrm{C} \mathrm{min-1}$. A full color version of this figure is available at Polymer Journal online.

film of 8-TTP-8 spin-coated at its liquid crystalline temperature. They indicate that the film is very uniform and has some crystal grains of $\sim 40 \mu \mathrm{m}$ in diameter, making it quite different from the vacuumdeposited films of pentacene and oligothiophenes resulting from the crystal growth of molecules on the substrate that have many and more irregular grains. Furthermore, the surface morphology of the film is so molecularly flat that a molecular step of $3.2 \mathrm{~nm}$, which is in good agreement with the molecular length of 8-TTP-8, is observed by AFM measurements, as shown in Figure 5a. These findings are not particular to 8 -TTP-8 but quite generally apply to various liquid crystals, irrespective of the presence of smectic phases. ${ }^{30}$

The crystalline thin films have a vertical alignment of molecules on the substrate because the XRD result in the out-of-plane configuration has only a small-angle region, as shown in Figure 5b. Aligned crystalline thin films are created by the molecules aligning in the liquid crystal phase, and the state is maintained after cooling to room temperature in the crystal phase. This is a suitable alignment for OFET devices. In fact, the OFET result of 8-TTP-8 indicates a mobility of over $0.1 \mathrm{~cm}^{2} \mathrm{Vs}^{-1}$ despite its small core size based on a terthiophene derivative. ${ }^{28}$ The crystalline thin film is in a liquid crystalline sandwich cell, where the molecules are aligned in a planar manner on the substrate, and the molecules are kept in a planar alignment on the substrate. The mobility evaluated by the time-of-flight technique is $0.2 \mathrm{~cm}^{2} \mathrm{Vs}^{-1}$, which is the same value as the FET mobility. ${ }^{31}$ These results indicate that the liquid crystalline materials can be used not only in planar devices such as FETs but also in vertical devices such as organic ELs and organic solar cells.

The liquid crystallinity of OFET materials helps to achieve good molecular alignment and crystallization by annealing for thin films of not only liquid crystalline polymer materials ${ }^{32}$ but also liquid crystalline small molecules. ${ }^{30}$ The FET mobilities increase twice by thermally annealing the liquid crystal phases. In liquid crystalline small molecules, annealing at the temperature in low-ordered smectic phases such as SmA is more effective than that at the temperature in highly ordered smectic phases.

\section{High durability for thermal processes}

OFET materials chemically modified with long alkyl chains exhibit low melting points, as described above, which is due to their weakened $\pi-\pi$ interactions. $\mathrm{C}_{8}$-BTBT melts at $\sim 10{ }^{\circ} \mathrm{C}$, which is not high enough for the thermal processes to occur in device fabrication. $\mathrm{C}_{8}$-BTBT exhibits a liquid-like smectic mesophase of $\mathrm{SmA},{ }^{33}$ which is responsible for the low thermal durability. This problem could be solved if the OFET materials exhibit any highly ordered smectic mesophase: because the highly ordered smectic mesophases exhibit a solid-like nature, their crystalline films can stay in film form when heated at their temperature range and go back to the crystal state when cooled down to the crystallization temperature; this gives the crystalline film high thermal durability. This was demonstrated with a SmE liquid crystal of 
8-Tp-BTBT, as shown in Figure 6a, which exhibits a SmE phase in the temperature range from 131 to $180^{\circ} \mathrm{C}$. 8 -Tp-BTBT crystalline films can maintain their film form and never melt into a droplet when heated at $150^{\circ} \mathrm{C}$, as shown in Figure $6 \mathrm{c}$.

Figure 6d exhibits FET mobility in bottom-gate top-contact FETs fabricated with $\mathrm{C}_{10}$-BTBT (10-BTBT-10) and 8-Tp-BTBT, which exhibit SmA and SmE phases, respectively, after being subjected to thermal stress at a given temperature for $5 \mathrm{~min}$. The FET fabricated with 8-Tp-BTBT can be operated well even after undergoing thermal stress at $150^{\circ} \mathrm{C}$ for $5 \mathrm{~min}$, whereas the FET from $\mathrm{C}_{10}$-BTBT is substantially degraded because the $\mathrm{C}_{10}$ - $\mathrm{BTBT}$ is melted, as shown in Figure $6 \mathrm{~b} .^{34,35}$

\section{A novel smectic liquid crystalline OFET material, Ph-BTBT-10}

Taking account of the advantages of highly ordered smectic liquid crystals for OFET materials discussed in the previous sections, Ph-BTBT-10 was designed and synthesized to demonstrate its high potential as a soluble OFET material, as shown in Figure 7a. Ph-BTBT-10 shows a narrow solubility of $2 \mathrm{gl}^{-1}$ in toluene at $20^{\circ} \mathrm{C}$ for solution processes and exhibits a SmE phase from 142 to $210^{\circ} \mathrm{C}$ in the heating process and from 210 to $98^{\circ} \mathrm{C}$ in the cooling process. ${ }^{2}$ Uniform polycrystalline thin films can be prepared by spincoating at a temperature for the SmE phase, for example, $110^{\circ} \mathrm{C}$, as shown in Figure 7b and c, with no cracking occurring due to the small difference in the thermal-expansion coefficients for the SmE phase and crystalline phase of the lattice.

OFETs fabricated with this film exhibit excellent p-channel operation, as shown in Figure 8a, with a FET mobility estimated to be $2.1 \mathrm{~cm}^{2} \mathrm{Vs}^{-1}$. The FET transfer characteristics were significantly improved, and the drain current dramatically increased up to $10^{-3} \mathrm{~A}$ when the FETs were thermally annealed at $120^{\circ} \mathrm{C}$ for $5 \mathrm{~min}$. The FET mobility in the saturation region was enhanced up to $22.4 \mathrm{~cm}^{2} \mathrm{Vs}^{-1}$, as shown in Figure $8 \mathrm{a}$. The variation of the FET mobility of Ph-BTBT-10 was shown to be as small as $<10 \%$ in a study of 49 devices. ${ }^{2}$ The FET mobility at room temperature was over $3 \mathrm{~cm}^{2} \mathrm{Vs}^{-1}$, even after being subjected to thermal stress at $200{ }^{\circ} \mathrm{C}$ for $5 \mathrm{~min} .^{2}$

As for the effect of thermal annealing, the X-ray diffraction patterns exhibited a clear change in the peaks at $3.4^{\circ}$ and $1.7^{\circ}$ before and after the thermal annealing, respectively, as shown in Figure $8 \mathrm{~b}$. These indicate that a mono-layer structure with a layer thickness of $26 \AA$ was transformed into a bilayer structure with a thickness of $52 \AA$ after the annealing, as shown in the schematic illustration of Figure $8 \mathrm{~b}$. In addition, a broad exothermic peak appeared in the temperature region of the DSC chart from 60 to $120^{\circ} \mathrm{C}$, in accordance with this change, indicating crystallization by heating, as shown in Figure 9. The quantum chemical calculation of the transfer integral for layered molecules produces a value of $8 \mathrm{meV}$, which cannot be ignored for carrier transport. Therefore, it is plausible that the enhanced mobility after the thermal annealing is due to the enhanced carrier transport channel, in addition to possible enhanced carrier transport within the molecular layers. All of these results indicate that a highly ordered smectic liquid crystalline organic semiconductor of Ph-BTBT-10 is a very promising material for OFETs.

\section{SUMMARY}

The current status of OFET materials including small-molecule and polymer OFET materials are reviewed, and the problems that remain for practical applications are discussed. As is described, the liquid crystallinity in soluble OFET materials is paid little attention but deserves further consideration. The novel liquid crystalline organic semiconductor of Ph-BTBT-10 is a good example that demonstrates how liquid crystallinity can be utilized to solve the problems of conventional OFET materials. Its high mobility of over $10 \mathrm{~cm}^{2} \mathrm{Vs}^{-1}$ in polycrystalline OFETs, which is comparable to the FET mobility of single-crystalline OFETs, indicates a more practical approach to achieving high mobility compared to that of their inorganic counterpart oxide FETs. Thus, we conclude that liquid crystallinity can be a powerful booster that potentiates the superiority of small-molecule OFET materials for practical applications.

\section{CONFLICT OF INTEREST}

The authors declare no conflict of interest.

\section{ACKNOWLEDGEMENTS}

This study was supported in part by JST-CREST, JST-A-step and JSPS KAKENHI, grant numbers 18850008, B21750188, B24750178 and $15 \mathrm{~K} 05662$.

1 Nelson, S. F., Lin, Y.-Y., Gundlach, D. J. \& Jackson, T. N. Temperature-independent transport in high-mobility pentacene transistors. Appl. Phys. Lett. 72, 1854-1856 (1998).

2 lino, H., Usui, T. \& Hanna, J. Liquid crystals for organic thin film transistor. Nat Commun. 6, 6828 (2015).

3 Sheraw, C. D., Jackson, T. N., Eaton, D. L. \& Anthony, J. E. Functionalized pentacene active layer organic thin-film transistors. Adv. Mater. 15, 2009-2011 (2003).

4 Ebata, H., Izawa, T., Miyazaki, E., Takimiya, K., Ikeda, M., Kuwabara, H. \& Yui, T. Highly soluble [1]Benzothieno[3,2-b]benzothiophene (BTBT) derivatives for high-performance, solution-processed organic field-effect transistors. J. Am. Chem. Soc. 129, 15732-15733 (2007).

5 Kang, M. J., Doi, I., Mori, H., Miyazaki, E., Takimiya, K., Ikeda, M. \& Kuwabara, H. Alkylated Dinaphtho[2,3-b:2',3'-f]Thieno[3,2-b]Thiophenes(Cn-DNTTs): organic semiconductors for high-performance thin-film transistors. Adv. Mater. 23, 1222-1225 (2011).

6 Okamoto, T., Mitusi, C., Yamagishi, M., Nakahara, K., Soeda, J., Hirose, Y., Miwa, K., Sato, H., Yamano, A., Matsushita, T., Uemura, T. \& Takeya, J. V-shaped organic semiconductors with solution processability, high mobility, and high thermal durability. Adv. Mater. 25, 6392-6397 (2013)

7 Mitsui, C., Okamoto, T., Yamagishi, M., Tsurumi, J., Yoshimoto, K., Nakahara, K. Soeda, J., Hirose, Y., Sato, H., Yamano, A., Uemura, T. \& Takeya, J. High-performance solution-processable $\mathrm{N}$-shaped organic semiconducting materials with stabilized crystal phase. Adv. Mater. 26, 4546-4551 (2014).

8 Tatemichi, S., Ichikawa, M., Koyama, T. \& Taniguchi, Y. High mobility n-type thin-film transistors based on $\mathrm{N}, \mathrm{N}$-ditridecyl perylene diimide with thermal treatments. Appl. Phys. Lett. 89, 112108 (2006).

9 Wilson, B., El-Nawawy, A. S. \& Ollis, W. D. Eight- and higher-membered ring compounds. Part X. Di-, tri-, and tetra-thiosalicylides. J. Chem. Soc. 1952, 3163-3167 (1952).

10 Tsumura, A., Koezuka, H. \& Ando, T. Macromolecular electronic device: field -effect transistor with a polythiophene thin film. Appl. Phys. Lett. 49, 1210-1212 (1986)

11 Fuchigami, H., Tsumura, A. \& Koezuka, H. Polythienylenevinylene thin-film transistor with high carrier mobility. Appl. Phys. Lett. 63, 1372-1374 (1993).

12 Sirringhaus, $H$., Brown, P. J., Friend, R. H., Nielsen, M. M., Bechgaard, K. Langeveld-Voss, B. M. W., Spiering, A. J. H., Janssen, R. A. J., Meijer, E. W., Herwig, P. \& de Leeuw, D. M. Two-dimensional charge transport in self-organized, high-mobility conjugated polymers. Nature 401, 685-688 (1998).

13 McCulloch, I., Heeney, M., Bailey, C., Genevicius, K., Macdonald, I., Shkunov, M., Sparrowe, D., Tierney, S., Wagner, R., Zhang, W., Chabinyc, M. L., Kline, R. J., Mcgehee, M. D. \& Toney, M. F. Liquid-crystalline semiconducting polymers with high charge-carrier mobility. Nat. Mater. 5, 328-333 (2006).

14 Tsao, H. N., Cho, D. M., Park, I., Hansen, M. R., Mavrinskiy, A., Yoon, D. Y., Graf, R., Pisula, W., Spiess, H. W. \& Mullen, K. Ultrahigh mobility in polymer field-effect transistors by design. J. Am. Chem. Soc. 133, 2605-2612 (2011).

15 Bronstein, H., Chen, Z., Ashraf, R. S., Zhang, W., Du, J., Durrant, J. R., Tuladhar, P. S., Song, K., Watkins, S. E., Geerts, Y., Wienk, M. M., Janssen, R. A. J., Anthopoulos, T., Sirringhaus, H., Heeney, M. \& McCulloch, I. Thieno[3,2-b]thiophene-diketopyrrolopyrrole-containing polymers for high-performance organic field-effect transistors and organic photovoltaic devices. J. Am. Chem. Soc. 133, 3272-3275 (2011).

16 Yan, H., Chen, Z., Zheng, Y., Newman, C., Quinn, J. R., Dotz, F., Kastler, M. \& Facchetti, A. A high-mobility electron-transporting polymer for printed transistors. Nature 457, 679-689 (2009).

17 Tseng, H. R., Phan, H., Luo, C., Wang, M., Perez, L. A., Patel, S. N., Ying, L., Kramer, E. J., Nguyen, T.-Q., Banan, G. C. \& Heeger, A. J. High-mobility field-effect transistors fabricated with macroscopic aligned semiconducting polymers. Adv. Mater. 26, 2993-2998 (2014).

18 Garnier, F., Yassar, A., Hajlaoui, R., Horowitz, G., Deloffre, F., Servet, B., Ries, S. \& Alnot, P. Molecular engineering of organic semiconductors: design of self-assembly 
properties in conjugated thiophene oligomers. J. Am. Chem. Soc. 115, 8716-8721 (1993).

19 Katz, H. E., Laquindanum, J. G. \& Lovinger, A. J. Synthesis, solubility, and field-effect mobility of elongated and oxa-substituted $\alpha, \omega$-dialkyl thiophene oligomers. extenstion of 'polar intermediate' synthetic strategy and solution deposition on transistor substrates. Chem. Mater. 10, 633-638 (1998).

20 Garnier, F., Hajlaoui, R., Kassmin, A. E., Horowitz, G., Laigre, L., Prozio, W., Aramanini, M. \& Provasoli, F. Dihexylquaterthiophene, a two-dimensional liquid crystal-like organic semiconductor with high transport properties. Chem. Mater. 10, 3334-3339 (1998).

21 Van Breemen, A. J. J. M., Herwig, P. T., Chlon, C. H. T., Sweelssen, J., Schoo, H. F. M., Setayesh, S., Hardeman, W. M., Martin, C. A., de Leeuw, D. M., Valeton, J. J. P., Bastiaansen, C. W. M., Broer, D. J., Popa-Merticaru, A. R. \& Meskers, S. C. J. Large area liquid crystal monodomain field-effect transistors. J. Am. Chem. Soc. 128, 2336-2345 (2005).

22 Funahashi, M., Zhang, F. \& Tamaoki, N. High ambipolar mobility in a highly ordered smectic phase of a dialkylphenylterthiophene derivative that can be applied to solutionprocessed organic field-effect transistors. Adv. Mater. 19, 353-358 (2007).

23 Oikawa, K., Monobe, H., Nakayama, K., Kimoto, T., Tsuchiya, K., Heinrich, B. Guillon, D., Shimizu, Y. \& Yokoyama, M. High carrier mobility of organic field-effect transistors with a thiophene-naphthalene mesomorphic semiconductor. Adv. Mater. 19, 1864-1868 (2007)

24 Pisula, W., Menon, A., Stepputat, M., Liebewirth, I., Kolb, U., Tracz, A Sirringhaus, H., Pakula, T. \& Müllen, K. A zone-casting technique for device fabrication of field-effect transistors based on discotic hexa-peri-hexabenzocoronene. Adv. Mater. 17, 684-689 (2005).

25 Meng, H., Sun, F., Goldfinger, M. B., Jaycox, G. D., Li, Z., Marshall, W. J. \& Blackman, G. S. High-performance, stable organic thin-film field-effect transistors based on Bis-5'-alkylthiophen-2'-yl-2,6-anthracene semiconductors. J. Am. Chem. Soc. 127, 2406-2407 (2005).

26 Funahashi, M. \& Hanna, J. Fast hole transport in a new calamitic liquid crystal of 2-(4'-Heptyloxyphenyl)-6-Dodecylthiobenzothiazole. Phys. Rev. Lett. 78, 2184-2187 (1997).

27 Tokunaga, K., lino, H. \& Hanna, J. Reinvestigation of carrier transport properties in liquid crystalline 2-phenylbenzothiazole derivatives. J. Phys. Chem. B. 111, 12041-12044 (2007).

28 lino, H. \& Hanna, J. Availability of liquid crystallinity in solution processing for polycrystalline thin films. Adv. Mater. 23, 1748-1751 (2011).

29 lino, H. \& Hanna, J. Liquid crystalline thin films as a precursor for polycrystalline thin films aimed at field effect transistors. J. Appl. Phys. 109, 074505 (2011).

30 lino, H. \& Hanna, J. Polycrystalline organic TFT fabricated by solution process using liquid crystalline material. Mol. Cryst. Liq. Cryst. 510, 259-267 (2009).

31 lino, H. \& Hanna, J. Availability of liquid crystalline molecules for polycrystalline organic semiconductor thin films. Jpn. J. Appl. Phys. 45, L867-L870 (2006).

32 Lucas, L. A., DeLongchamp, D. M., Vogel, B. M., Lin, E. K., Fasolka, M. J., Fischer, D. A., McCulloch, I., Heeney, M. \& Jabbour, G. E. Combinatorial screening of the effect of temperature on the microstructure and mobility of a high performance polythiophene semiconductor. Appl. Phys. Lett. 90, 012112 (2007).

33 Kosata, B., Kozmik, V., Svoboda, J., Novotna, V., Vanek, P. \& Glogarova, M. Novel liquid crystals based on [1]benzothieno[3,2-b][1]benzothiophene. Liq. Cryst. 30, 603-610 (2003)

34 lino, H., Kobori, T. \& Hanna, J. High uniformity and high thermal stability of solutionprocessed polycrystalline thin films by utilizing highly ordered smectic liquid crystals. Jpn. J. Appl. Phys. 51, 11PD02 (2012).

35 lino, H. Kobori, T. \& Hanna, J. Improved thermal stability in organic FET fabricated with a soluble BTBT derivative. J. Non Cryst. Solid 358, 2516-2519 (2012). 